\title{
POSSÍVEIS ARTICULAÇÕES ENTRE OS CONCEITOS DE TECNOLOGIA E COMPETÊNCIAS NA FORMAÇÃO PROFISSIONAL DOCENTE
}

\author{
Erlande D Ávila Nascimento; Rosa Oliveira Marins Azevedo \\ Instituto Federal de Educação, Ciência e Tecnologia do Acre - IFAC; Instituto Federal de \\ Educação, Ciência e Tecnologia do Amazonas - IFAM \\ erlande.nascimento@ifac.edu.br; rosamarins13@gmail.com \\ 10.15628/rbept.2017.5561 \\ Artigo submetido em jan/2017 e aceito em out/2017
}

\section{RESUMO}

O presente artigo é resultado de várias atividades desenvolvidas na disciplina Fundamentos para a Formação de Professores do Ensino Tecnológico do Mestrado Profissional em Ensino Tecnológico do Instituto Federal de Educação, Ciência e Tecnologia do Amazonas (MPET/IFAM). O objetivo geral é discutir a formação profissional docente, trazendo a concepção do conceito de tecnologia e abordando as competências como tendência na formação de professores. Foram realizadas atividades, como: fichamentos, resumos, levantamentos de ideias e conceitos relevantes, tendo como sustentação teórica Ferreti (2002); Imbernón (2006), Oliveira (2008), Pinto (2005), Penã (2003), Ghedin (2009), Perrenoud (1999). De maneira mais específica pretendemos: (1) discutir algumas concepções do termo tecnologia, em que procuramos estabelecer algumas classificações; (2) mostrar o conceito de competência e seu processo formativo e (3) articular o conceito de tecnologia com as novas competências de ensinar, segundo Philippe Perrenoud. O artigo está organizado em cinco partes: (a) introdução com abordagem geral de todo o trabalho; (b) o conceito de tecnologia: sentidos do termo; (c) O conceito de competências: uma visão formativa; (e) para além do conceito de tecnologia: as competências e a formação docente e (e) considerações finais.

Palavras-Chaves: Tecnologia, Formação profissional docente, Competências.

\section{ABSTRACT}

This article is the result of several activities in the discipline Fundamentals for Teacher Training Technological Education Professional Master in Technological Education Federal Institute of Education, Science and Technology Amazon (MPET / IFAM). The overall objective is to discuss teacher training, bringing the design of the concept of technology and addressing the skills as a trend in teacher education. Activities were carried out: fichamentos, abstracts, ideas surveys and relevant concepts and the theoretical support Ferreti (2002); Imbernón (2006), Oliveira (2008), Pinto (2005), Peña (2003) Ghedin (2009), Perrenoud (1999). More specifically we aim to: (1) discuss some concepts of the term technology, we seek to establish some classifications; (2) show the concept of competence and its formative process and (3) to articulate the concept of technology with new skills to teach, according to Philippe Perrenoud. The paper is organized into five parts: (a) introduction with the general approach of the entire work; (B) the concept of technology: the word senses; (C) The concept of skills: a training vision; (E) in addition to the concept of technology: skills and teacher training and (e) final considerations.

KEYWORDS: Technology, Training teachers professional, Skills. 


\section{INTRODUÇÃO}

As tecnologias têm sido colocadas em prática, no processo de ensino aprendizagem, como um instrumento didático-pedagógico e utilizadas por professores em diversas áreas do conhecimento.

Partindo do estudo do conceito que os professores têm de tecnologia, acreditamos que numa visão de formação profissional docente, a constatação sobre esse conceito passa a ser um ponto de reflexão sobre seu sentido, podendo permitir mudanças em sua prática docente que levem a melhoria e ampliação de sua prática profissional.

Ao pensar em melhorar sua prática profissional, o professor precisa dispor de conhecimentos que permitam alcançar tal propósito. Esses conhecimentos tanto podem ter origem em seu trabalho diário quanto no conhecimento acadêmico, e tendem a ser ampliados na experiência pedagógica, no ensinar. Segundo Fontana e Cruz (1997), “Ensinar é transmitir conhecimentos, técnicas, valores, é deixar o outro fazer, orientando, explicando, 'dando a receita', fazendo junto [...]".

Devemos antes de tudo, diagnosticar e mapear as principais dificuldades e, com os resultados em mãos, promover estratégias de ensino capazes de buscar a interface entre teoria e prática, porquanto não restam quaisquer dúvidas de que o alunado quer compreender o porquê de se estudar temas tão complexos, por outras palavras, qual a verdadeira razão desses estudos? Onde e como utilizá-lo no cotidiano?

É cediço afirmar que tais respostas só serão possíveis se houver um novo olhar acerca de como ensinar e para que ensinar, quais estratégias didáticas e suportes contribuirão para um ensino verdadeiramente instigante e significativo, capaz de minimizar perspectivas negativas, construídas dentro e fora das escolas.

Nesse corolário, aulas interativas e inovadoras à luz das novas ferramentas tecnológicas surgem como caminho a ser trilhado em busca de um ensino-aprendizagem prazeroso, eficiente e desafiador.

É preciso pensar a formação de professores a partir de um pensamento reflexivo, explorando potencialidades didáticas, sabendo explicitar as próprias práticas e estabelecendo o seu próprio balanço de competências e programa de formação.

Nessa perspectiva, intencionamos, com o presente artigo, discutir a formação profissional docente, trazendo a concepção do conceito de tecnologia e abordando as competências como tendência na formação de professores.

\section{O CONCEITO DE TECNOLOGIA: SENTIDOS DO TERMO}

O conceito de tecnologia relaciona-se ao uso dos meios tecnológicos, que atendam às necessidades do aprendiz e que possa torná-lo humanizado e independente, como afirma Penã (2003, p. 9):

A sociedade neoliberal e informacional promoveu mudanças nas relações humanas, acelerando o processo de desigualdades sociais e o empobrecimento. A tecnologia tem se transformado num instrumento a serviço da política de exclusão, pois, o acesso às novas técnicas é ditado pelas condições materiais de cada indivíduo. Nesse sentido, a educação deve ser concebida como um meio de resistência e 
transformação das injustiças sociais, promovendo o desenvolvimento integral dos educandos, e, através das novas tecnologias possibilitar a inclusão digital, num caminho para a emancipação, para a humanização e ampliação do conceito de cidadania.

O autor acrescenta que, diante da relação entre educação e tecnologia, formando uma sociedade momentânea movida pelo neoliberalismo e globalização, faz-se necessário a criação de uma sociedade mais justa, entendendo que

Se o progresso é inerente ao ser humano, é necessário que ele não seja um fim em si mesmo, mas um meio que possibilite a criação de uma sociedade mais justa, mais humana e igualitária. Isso só será possível a partir de uma educação integral, numa política consciente para a utilização dos recursos tecnológicos, beneficiando a todos, sem exceção, superando as contradições sociais e a opressão. (PENÃ, 2003. p. 10).

Nessa discussão, Pinto (2005) contribui alertando para a necessidade de classificar os diversos sentidos do termo tecnologia, onde considera legítimo identificar quatro significados principais: a) o significado etimológico, a tecnologia sendo a teoria, a ciência, o estudo, a discussão da técnica, e ainda a arte, habilidade do fazer e as profissões. A tecnologia, neste primeiro sentido, aparece com um valor fundamental e exato de logos da técnica'; b) a tecnologia equivale pura e simplesmente a técnica, um sinônimo que segundo o autor, poderá ser fonte de engano para compreensão sociológica e filosófica da tecnologia; c) no terceiro sentido, que está estreitamente ligado ao segundo, a tecnologia é o conjunto de todas as técnicas de que dispõe uma determinada sociedade em qualquer fase histórica de seu desenvolvimento, sendo importante medir o grau de avanço das forças produtivas de uma sociedade; d) considerado pelo autor o principal sentido do termo, a ideologização da técnica ou ideologia da técnica.

Segundo Pinto (2005), para termos uma interpretação científica, precisaremos primeiramente conhecer a teoria geral da técnica, que está elencada nos seguintes objetos: (a) a classificação das técnicas; (b) a história das técnicas; (c) a rentabilidade das técnicas; (d) o papel das técnicas na organização das relações entre os homens. 0 autor afirma que devemos ter o cuidado de observarmos que existem conhecimentos teóricos e práticos, mas que todos são importantes para o bem-estar da humanidade.

Além disso, conforme o autor, é importante um esclarecimento teórico a respeito do conceito de tecnologia, como epistemologia da técnica, como comenta:

Se a técnica configura um dado da realidade objetiva, um produto da percepção humana que retorna ao mundo em forma de ação, materializado em instrumentos e máquinas, e entregue à transmissão cultural, compreende-se tenha obrigatoriamente de haver ciência que o abrange e explora, dando em resultado um conjunto de formulações teóricas, recheadas de complexo e rico conteúdo epistemológico. Tal ciência deve ser chamada "tecnologia", conforme o uso generalizado na composição das denominações científicas. (PINTO, 2005, p. 221). 
Com base nessa discussão, Pinto (2005) esclarece que a tecnologia é a ciência da técnica, para ter a técnica é necessário um saber. Quando discutimos algum problema relacionado à tecnologia, estamos discutindo a técnica. Então, quando mencionamos tecnologia como epistemologia da técnica, estamos dizendo: tecnologia é a ciência da técnica.

Como é possível articular essa discussão ao conceito de competências como uma tendência na formação profissional docente?

\section{O CONCEITO DE COMPETÊNCIAS: UMA VISÃO FORMATIVA}

O conceito de competência na abordagem de vários autores, incluindo Ghedin (2009), caracteriza-se pela polissemia de sentidos, tornando a reflexão mais abrangente em seus diversos aspectos.

Segundo Rojas (1999 apud GHEDIN, 2009, p. 17) “[...] a novidade no conceito de competência está na ideia de comunicação em rede e integração de funções”. De acordo com Pimenta (2002 apud GHEDIN, 2009, p. 18), "[...] as mais diversas interpretações, estabelece uma teia de relação entre saber, saber-fazer e saber-ser, com ênfase a este último [...]”.

Perrenoud (1999 apud GHEDIN, 2009, p.18) define competência como

[...] a capacidade de agir eficazmente em um determinado tipo de situação, apoiado em conhecimentos, mas sem limitar-se a eles. Agir de modo competente, portanto, significa mobilizar um conjunto de recursos cognitivos e afetivos, dentre os quais estão os conhecimentos.

O autor diz que antes de chegar a essa definição de competência, levado a três pistas falsas:

1. A competência por objetivo: retorno ao tradicional dando ênfase no ensino centrado apenas na aquisição de conhecimentos;

2. Oposição entre competência e desempenho: o desempenho observado seria um indicador mais ou menos confiável de uma competência indiretamente;

3. Competência considerada como uma faculdade genérica, uma potencialidade de qualquer mente humana: os seres humanos certamente têm a faculdade, ancorada em seu patrimônio genético, contudo, nenhuma competência é estimulada desde o início.

Diz que estas pistas estão equivocadas, pois a competência se constrói na prática apoiada em teorias, ou seja, agir de maneira reflexiva.

A tendência das teorias das competências entra no Brasil através de políticas públicas do governo de FHC, que segundo Ghedin (2009) dá uma nova roupagem ao neotecnicismo em que o professor precisa ter o saber para ser competente, ou seja, o professor precisa ser competente no singular e não no plural. Isso quer dizer que, existe um conjunto de elementos que reunidos formam a competência do professor e não as competências (situação + ação = conhecimento).

Rios (2001-2004 apud GHEDIN, 2009, p.21) diz que um professor "[...] é competente porque é competente do ponto de vista ético e político. Essa é a competência do professor."

Esse conceito não foi suficientemente abordado como tema de pesquisa e necessita ser aprofundado para que se possam compreender suas possibilidades no processo de formação de professores. Isso é uma crítica à perspectiva emancipatória. 
Numa perspectiva emancipatória, a autonomia depende de condições de trabalho, de melhores salários, de políticas de formação, de um conjunto de outras questões que não estão postas pelas teorias das competências, que são fundamentais e devem ser consideradas ao longo do processo de profissionalização dos professores.

Para Ramos (apud s/d apud Ferreti, 2002) a competência como tendência é aquela que parte de situações concretas, recorrendo às disciplinas na medida das necessidades requeridas por essas situações, e não de conteúdos disciplinares existentes considerados importantes.

Segundo Ramos (s/d), tal tendência é entendida como aquela compatível com o que, segundo os discursos correntes, é demandado dos "novos" trabalhadores das empresas flexibilizadas.

Diante disso, faz uma indagação: tal tendência conduz à autonomia dos sujeitos a ela expostos ou à sua mera adaptação às mudanças no trabalho e na vida social?

Para Perrenoud (1999), os professores que assumem o ensino por competências se apropriam de responsabilidades na escolha de práticas sociais. Além disso, modificam suas próprias visões a respeito da cultura e da sociedade, principalmente, ao construir conhecimentos. Aqueles que não optarem por essa tendência poderão continuar trabalhando a partir de seus modelos de professores, de forma segregada e disciplinar.

Além disso, os professores, segundo Perrenoud(1999), precisam sentir-se responsáveis pela formação global do aluno. 0 ensino por competências propõe a educação integral do educando, de forma que não haja descompartimentação das disciplinas. Mesmo que, ao trabalhar com competências, o educando mobilize conhecimentos que também são de ordem disciplinar, o importante é que ele saiba transpor os conhecimentos de diferentes áreas, utilizando-os como componentes da realidade.

Se esse aprendizado não for associado a uma ou mais práticas sociais, suscetíveis de ter um sentido para os alunos, será rapidamente esquecido, considerado como um dos obstáculos a serem vencidos para conseguir um diploma, e não como uma competência a ser assimilada para dominar situações da vida (PERRENOUD, 1999).

Na visão de Ghedin (2009) o problema em centralizar a formação do professor na teoria das competências implica reduzir o problema da educação, exclusivamente, a incompetência do professor.

Ghedin (2009, p.22) ainda afirma que

[...] o fracasso da educação brasileira é um fracasso político, é um fracasso moral, um fracasso ético, não é um fracasso da competência do professor. É um fracasso da competência, da ingerência do Estado na educação e não dos professores que se esforçam para salvar aquilo que a política e os políticos estatais já abandonaram há muito tempo.

O que se deve ter claro é que, segundo Perrenoud (1999), o professor precisa dominar conhecimentos a serem ensinados, ser capaz de ministrar aulas, envolver os alunos em suas aprendizagens e organizar e dirigir situações de aprendizagem. Enfatiza a necessidade dessas novas competências, para contribuir diretamente no desempenho e cumprimento de seu papel educacional.

Durante décadas, muitos professores eram categóricos na afırmação de que "teoria associada à prática, traz resultados mais significativos". O certo é que a aprendizagem é construída através da compreensão dos sentimentos e das necessidades do aluno, dandoIhe ferramentas práticas para que ele possa construir seu aprendizado. 


\section{PARA ALÉM DO CONCEITO DE TECNOLOGIA: AS COMPETÊNCIAS E A FORMAÇÃO DOCENTE}

As transformações que se percebem no mundo atual, vão evidentemente muito além de uma simples mudança de tecnologias de comunicação e informação. As tecnologias, chamadas de comunicação e informação, desempenham um papel central na sociedade. A educação não é uma área em si, mas um processo permanente de construções em pontes entre o mundo da escola e o universo que nos cerca.

A nossa visão tem de incluir estas transformações, não é apenas a técnica de ensino que muda, incorporando uma nova tecnologia, é a própria concepção de ensino que tem de repensar os seus caminhos.

O desenvolvimento tecnológico que se faz necessário hoje em dia para o estabelecimento de uma economia competitiva, exige recursos humanos altamente qualificados. 0 desenvolvimento econômico pressupõe não só a capacidade de utilizar as tecnologias existentes, mas de adaptá-las e de promover inovações.

Por este viés de análise, Imbernón (2006, p. 21) considera o profissional da educação como

[...] um agente dinâmico cultural, social e curricular, capaz de tomar decisões educativas, éticas e morais, de desenvolver o currículo em um contexto determinado e de elaborar projetos e materiais curriculares com a colaboração dos colegas, situando o processo em um contexto específico controlado pelo próprio coletivo.

Afirma em relação a inovação educativa e profissão docente, que a inovação nas instituições educativas não se efetivará sem a proposta de um novo conceito de profissionalização docente, que deve alterar práticas tradicionais tidas intrínsecas à profissão docente. Essa visão, pressupõe que o professor participe ativa e criticamente do processo de inovação e mudança, como sujeito de sua formação, tornando o ambiente mais propício as práticas coletivas nas instituições educativas.

Além das discussões apontadas acima, Perrenoud (1999; 2000 apud GHEDIN, 2009, p.19) reflete e explica que

[...] a competência inexiste sem o conhecimento e que, no entanto, se traduz num conhecimento para a ação, refletido na realidade, e fundamentado na experimentação, é possível inferir que quando se fala de competência não se está falando realmente de algo novo, mas de uma atualização de antigas teorias pedagógicas, como a ideia de leitura do mundo de Freire (1987) ou a aula passeio de Freinet (apud ELIAS, 1997), ambas baseadas na valorização da experiência, da realidade de vida dos alunos.

Do mesmo modo, discutir possíveis articulações entre o conceito de tecnologia e competências na formação docente e profissional, não significa uma discussão inovadora, mas um modo inovador de pensar possibilidade de formação docente, que precisa ter como foco o próprio trabalho docente, no sentido de refletir mudanças em sua ação pedagógica para melhoria e ampliação de sua prática profissional. 


\section{CONSIDERAÇÕES FINAIS}

Neste estudo, a discussão procurando possíveis articulações entre os conceito de tecnologia e competências na formação profissional docente, permitem inferir que:

- quando discutimos algum problema relacionado a tecnologia, estamos discutindo a técnica. Então, quando mencionamos tecnologia como epistemologia da técnica, estamos dizendo: tecnologia é a ciência da técnica;

- as competências estabelecem as mais diversas interpretações, estabelece uma teia de relação entre saber, saber-fazer e saber-ser, como uma abordagem maior no saber-ser;

- o conceito de competência vai além de capacidade de agir eficazmente em um determinado tipo de situação, apoiado em conhecimentos, pois significa também mobilizar um conjunto de recursos cognitivos e afetivos para atuar frente a uma situação real;

- ao assumir as competências, os professores se apossam de responsabilidades na escolha de práticas sociais;

- o professor deve dominar saberes a serem ensinados, ser capaz de ministrar aulas, envolver os alunos em suas aprendizagens e organizar e dirigir situações de aprendizagem;

- há necessidade de o professor mobilizar novas competências, para contribuir diretamente no desempenho e cumprimento de seu papel educacional;

Assim,é possível dizer quearticular tecnologia e competências naformação profissional docente implica considerar a vivência pedagógica do professor como canal para se efetivar mudanças relativas as questões do trabalhos docente que exigem enfrentamento e busca de alternativa pedagógica.

Essas considerações salientam a importância de o professor deve refletir sobre a sua própria prática para produzir conhecimentos que lhe permita mobilizar um conjunto de recursos cognitivos (conhecimentos) para realizar de forma competente, com os pares, uma tarefa real, valorizando e aprendendo com sua experiência para um trabalho pedagógico docente consciente e autônomo.

\section{REFERÊNCIAS}

1. FERRETI, Celso João. A pedagogia das competências: Autonomia ou adaptação? Educ. Soc., Campinas, vol. 23, n.81, p. 299-306, dez. 2002.

2. FONTANA, Roseli; CRUZ, Nazaré. Psicologia do Trabalho Pedagógico. São Paulo: Atual, 1997.

3. GHEDIN, Evandro. Tendências e dimensões da formação do professor na contemporaneidade. In: CONGRESSO NORTE PARANAENSE DE EDUCAÇAO FÍSICA ESCOLAR, 4. 2009, Londrina. Anais...Londrina 2009: UEL, 2009. p.1-28

4. OLIVEIRA, Eva Aparecida. A técnica, a techné e a tecnologia. Itinerarius - Revista Eletrônica do curso de Pedagogia do Campus Jataí, UFG, vol. 2, n. 5, jul/dez. 2008, p. 1-13. Disponível em: http://www.revistas.ufg.br/index.php/ritref/article/download/20417/11905

5. PERRENOUD, Philippe. Avaliação da excelência à regulação das aprendizagens: entre duas lógicas. Porto Alegre: Artmed, 1999.

6. PERRENOUD, Phillipe et al. As competências para ensinar no século XXI: a formação dos professores e o desafio da educação.1. ed. Porto Alegre: ARTMED, 2002. 
7. PIMENTA, Neylanne Aracely de Almeida. A formação de professores orientada por competência: análise de conceitos e de um curso no Estado do Amazonas. Natal: Universidade Federal do Rio Grande do Norte, 2002 (Tese de Doutorado).

8. PIMENTA, Selma Garrido e GHEDIN, Evandro. Professor reflexivo no Brasil: gênese e crítica de um conceito. São Paulo: Cortez, 2002.

9. PINTO, Álvaro Vieira. O Conceito de Tecnologia. Rio Janeiro: Contraponto, 2005. $2 v$. 